\title{
Complementation Analysis of Fibroblasts from Peroxisomal Fatty Acid Oxidation Deficient Patients Shows High Frequency of Bifunctional Enzyme Deficiency Plus Intragenic Complementation: Unequivocal Evidence for Differential Defects in the Same Enzyme Protein
}

\author{
E. G. van Grunsven,* C. W. T. van Roermund,* S. Denis,* and R. J . A. Wanders*, ${ }^{* 1}$ \\ University Hospital Amsterdam, Academic Medical Center, Division of *Clinical Chemistry and †Pediatrics, \\ Emma Children's Hospital, P.O. Box 22700, 1100 DE Amsterdam, The Netherlands
}

Received May 1, 1997

In the last few years many patients have been reported with a defect in peroxisomal fatty acid $\beta$-oxidation of unknown origin. Using a combined approach based on direct activity measurements of straightchain acyl-CoA oxidase and complementation analysis after somatic cell fusion of fibroblasts, we have now classified 13 patients into 4 distinct groups representing different gene defects. Remarkably, we found intragenic complementation in group 2 so that group 2 is in fact made up of 3 distinct subgroups. The underlying basis for this peculiar phenomenon probably has to do with the fact that bifunctional protein harbors two catalytic activities including enoyl-CoA hydratase and 3-hydroxyacyl-CoA dehydrogenase. In group 2A enoyl-COA hydratase and 3-hydroxyacyl-COA dehydrogenase are defective whereas in group $2 B$ and $2 C$ either the hydratase or 3-hydroxyacyl-CoA dehydrogenase component of the bifunctional protein is deficient. () 1997 Academic Press

Peroxisomes are subcellular organelles which play an indispensable role in cellular metabolism. The importance of peroxisomes in man is stressed by the existence of a group of inherited disorders in man in which there is an impairment in one or more peroxisomal functions [1,2]. The prototype of this group of disorders is the Zellweger syndrome in which morphologically distinguishable peroxisomes are absent [3] due to mutations in one of the genes involved in peroxisomes biogenesis [1].

\footnotetext{
${ }^{1}$ Corresponding author: Fax: 0031-20-696 2596; E-mail: wanders@ amc.uva.nl.
}

One of the most important functions of peroxisomes, at least in higher eukaryotes, is the $\beta$-oxidation of fatty acids and fatty acid derivatives [4,5]. Although the mechanism of $\beta$-oxidation in peroxisomes is identical to that in mitochondria, $\beta$-oxidation in the two organelles fulfils separate purposes. Indeed, mitochondria catalyse the oxidation of the bulk of fatty acids derived from our daily diet, notably long-chain fatty acids, whereas peroxisomes are involved in the $\beta$-oxidation of a distinct set of fatty acids, including very-long-chain fatty acids (C24:0, C26:0 etc), di- and trihydroxycholestanoic acid, the precursors of the primary bile acids chenodeoxycholate and cholate, and pristanic acid $(2,6,10$, 14-tetramethylpentadecanoic acid). The latter is the $\alpha$ oxidation product of phytanic acid (see [6]).

In the last few years many patients have been re ported with a defect in peroxisomal $\beta$-oxidation of unknown origin (see [2] for references). Resolution of the underlying defect(s) in these patients is difficult especially since the individual peroxisomal $\beta$-oxidation enzyme activities are very hard to measure especially in fibroblasts with the exception of acyl-CoA oxidase. This is due to the presence of the mitochondrial $\beta$-oxidation enzymes catalyzing the same reactions, making differential analysis of the peroxisomal $\beta$-oxidation enzymes in homogenates virtually impossible.

We have now studied 13 patients with a defect in peroxisomal $\beta$-oxidation of unknown origin using direct acyl-CoA oxidase activity measurements and complementation analysis. The results show strong overrepresentation of one particular complementation group which contains 3 subgroups, probably representing differential defects within the same multifunctional $\beta$ oxidation enzyme with both hydratase and 3-hydroxyacyl-CoA dehydrogenase activities. 


\section{TABLE I}

Biochemical Characteristics of the 13 Patients with an Unknown Defect in Peroxisomal $\beta$-Oxidation

Fibroblasts

\begin{tabular}{|c|c|c|c|c|}
\hline \multirow[b]{2}{*}{ Patients } & \multicolumn{3}{|c|}{$\begin{array}{c}\text { Fatty acid oxidation } \\
\text { rate }^{\mathrm{b}}\end{array}$} & \multirow{2}{*}{$\begin{array}{c}\text { Acyl-CoA } \\
\text { oxidase activity }\end{array}$} \\
\hline & C26:0-level & C26:0 & Pristanic acid & \\
\hline 1,2 & $\uparrow$ & $\downarrow$ & $\mathrm{N}$ & $\downarrow$ \\
\hline $3-13$ & $\uparrow$ & $\downarrow$ & $\downarrow$ & $\mathrm{N}$ \\
\hline
\end{tabular}

a $\mu \mathrm{mol} / \mathrm{L}$.

${ }^{\mathrm{b}} \mathrm{pmol} / \mathrm{h} . \mathrm{mg}$ protein.

\section{MATERIALS AND METHODS}

Cell culture and complementation studies. Fibroblasts were grown from skin biopsies using standard culture conditions conditions [7]. Cells were subsequently fused or cocultivated according to Brul et al. [8]. The fused cells were cultured for 3 days in Dulbecco Modified Eagles Medium (DMEM) without Fetal Calf Serum (FCS) after which the occurrence of complementation was tested by means of pristanic acid $\beta$-oxidation which was performed as described before for cultured skin fibroblasts [7]. The same procedure was also used for $\left[1-{ }^{14} \mathrm{C}\right]$ hexacosanoic acid (C26:0) $\beta$-oxidation activity measure ments in fibroblasts [7].

Acyl-CoA oxidase activity measurements. the activity of the straight-chain acyl-CoA oxidase was measured in fibroblasts homogenates using $\left[{ }^{14} \mathrm{C}\right]$ palmitoyl-COA according to the procedure described by Hashimoto and coworkers [9].

Very-long-chain fatty acids. were measured in plasma according to previously published methods [10].

Patients. The patients studied in this paper displayed all the clinical and biochemical abnormalities described in literature for peroxisomal fatty acid oxidation disorders (see [1,2] for details) including elevated plasma very-long-chain fatty acids, deficient fatty acid oxidation in fibroblasts but normal de novo plasmalogen biosynthesis and the normal appearrance of peroxisomes in fibroblasts upon catalase-immunefluorescence (see [11]).

\section{RESULTS}

Table l lists the most important biochemical findings in the group of 13 patients studied in this paper. In all 13 patients el evated C26:0-levels were found in plasma as well as in fibroblasts. In accordance with these data C26:0 $\beta$-oxidation activity in fibroblasts was deficient in all cases. The results obtained show no difference between the patients. However, when pristanic acid $\beta$ oxidation was measured in the patients' fibroblasts, we found clear differences: in 11 of the 13 patients pristanic acid oxidation was deficient, whereas in 2 patients oxidation was normal. A likely possibility for the observed difference between the two groups of patients would be that there is a deficiency of the straight-chain acyl-CoA oxidase in patients 1 and 2, since the latter enzyme accepts C26:0-CoA but not pristanoyl-CoA as substrate [12]. Pristanoyl-CoA is known to be handled by a separate oxidase, called branched-chain acyl-CoA oxidase [12]. Direct measurement of straight-chain acyl-CoA oxidase activity in fibroblast homogenates using the el egant method described in [9] indeed showed a deficiency of this enzyme in patients 1 and 2, with normal activity in the 11 remaining patients (Table I).

Peroxisomal enoyl-CoA hydratase, 3-hydroxyacylCoA dehydrogenase and thiolase activities cannot be measured directly in fibroblast homogenates due to the presence of their mitochondrial counterparts, catalyzing the same reactions. For this reason we selected another approach to find out whether the 11 remaining patients were genetically homogeneous or not. Genetic complementation analysis after somatic cell fusion is the method of choice for this purpose [8,13-16].

Fibroblasts from a patient with an established deficiency of the peroxisomal bifunctional protein were selected as reference cell line [17]. All 11 patient cell lines were fused with the bifunctional protein deficient cell line and complementation was assessed by measuring pristanic acid $\beta$-oxidation in the fused cells. As a control, cells were not fused but only grown together followed by pristanic acid $\beta$-oxidation measurements in the cocultivated cells (results given in Table II between brackets).

The results of Table II show that 9 out of the 11 patient cell lines tested failed to show complementation with about equal rates of $\beta$-oxidation in fused and cocultivated cells (Table II, left column). Complementation was only observed with cell lines 12 and 13 . Inter-

\section{TABLE II}

Results of Complementation Studies Using Fibroblasts from Patients 3-13 and Two Established Patient Cell Lines (Bifunctional Protein Deficiency (BP-Deficiency) and Zellweger Syndrome)

\begin{tabular}{lcc}
\hline & $\begin{array}{c}\text { Pristanic acid } \beta \text {-oxidation activity } \\
\text { in fused/cocultivated cells }\end{array}$ \\
\cline { 2 - 3 } $\begin{array}{c}\text { Patient cell line } \\
\text { studied }\end{array}$ & \multicolumn{2}{c}{ Fusion partner: } \\
\cline { 2 - 3 } No. 3 & $24(6)$ & Zellweger \\
No. 4 & $6(4)$ & $225(0)$ \\
No. 5 & $10(11)$ & $251(3)$ \\
No. 6 & $0(0)$ & $393(11)$ \\
No. 7 & $0(0)$ & $509(1)$ \\
No. 8 & $7(0)$ & $432(0)$ \\
No. 9 & $0(6)$ & $317(0)$ \\
No. 10 & $1(1)$ & $322(8)$ \\
No. 11 & $5(6)$ & $457(0)$ \\
No. 12 & $657(36)$ & $340(25)$ \\
No. 13 & $307(15)$ & $280(16)$ \\
\hline
\end{tabular}

${ }^{a}$ Rates in pmol/h.mg protein. 


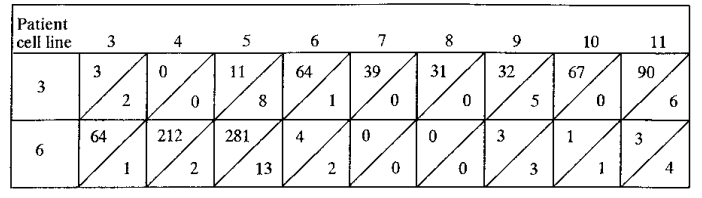

FIG. 1. Complementation analysis of fibroblasts belonging to complementation group 2 representing bifunctional protein deficiency. Cells from patients 3 and 6 were either fused or cocultivated with cells from $3,4,5,6,7,8,9,10$ and 11 followed by pristanic acid $\beta$-oxidation measurements. Numbers above the diagonal line represent fused cells, those below the line represent cocultivated cells.

estingly, when the latter two cell lines were fused together, clear complementation was observed (pristanic acid $\beta$-oxidation in fused and cocultivated cells: 256 and $30 \mathrm{pmol} / \mathrm{h}$. mg protein, respectively). These results suggest different genetic defects in patients 12 and 13 .

To rule out that the lack of complementation observed in Table II with patient cell lines 3-11 was artifactual, each patient cell line was fused with cells from a Zellweger patient. In such cells pristanic acid $\beta$-oxidation is deficient due to a defect in peroxisome biogenesis but not peroxisomal $\beta$-oxidation per se (see [1] for discussion). The results of Table II (right column) show clear complementation in all cases.

Taken together, the results of Table II show strong overrepresentation of one particular complementation group to which 9 of the 13 patients studied in this paper belong. Since the patient with established bifunctional protein deficiency (see [17]) also belongs to this group, the underlying defect in the 9 patients has to be at the level of the bifunctional enzyme, catalyzing the second and third reactions of peroxisomal $\beta$-oxidation.

In subsequent experiments fibroblasts from the 9 patients belonging to the same, large complementation group, were fused with one another. Interestingly, in some of these combinations clear complementation was observed as shown in Fig. 1. Indeed, if fibroblasts from patient 3 for instance were fused with fibroblasts from patient 6 , the rate of pristanic acid $\beta$-oxidation was found to be $64 \mathrm{pmol} / \mathrm{h} . \mathrm{mg}$ protein in contrast to a value of $1 \mathrm{pmol} / \mathrm{h}$.mg protein for the cocultivated combination. Fusion of patient cell line 3 with cells from patients 7, 8, 9, 10 and 11 also showed complementation, whereas cell lines 4 and 5 failed to show complementation with patient cell line 3 . In accordance with these results, no complementation was observed in fusions between cell line 6 and cell lines 7, 8, 9, 10 and 11, whereas cell line 6 did show complementation with cell lines 4 and 5 .

Taken together, the data of Fig. 1 suggest intragenic complementation with 3 subgroups within the group of bifunctional protein deficiency (Table III).

\section{DISCUSSION}

In the past many patients have been described in literature with a defect in peroxisomal $\beta$-oxidation of unknown origin [2]. In this paper we have used a combined approach involving measurement of straightchain acyl-COA oxidase activity in fibroblast homogenates and complementation analysis to identify the underlying defects. The results revealed a deficiency of straight-chain acyl-CoA oxidase in patients 1 and 2 . Subsequent complementation studies using fibroblasts from a patient with an established bifunctional protein deficiency as reference cell line [17], showed lack of complementation in 9 out of the 11 patients studied, thus suggesting that bifunctional protein is affected in all these 9 patients. The 2 remaining patients were found to belong to separate groups involving different, as yet unknown gene products (Table III).

Remarkably, we found intragenic complementation within the group of 9 bifunctional protein deficient patients so that this group is in fact made up of 3 subgroups (Table III). The underlying basis for this remarkable phenomenon probably has to do with the fact that the peroxisomal bifunctional enzyme harbors both enoyl-CoA hydratase and 3-hydroxyacyl-CoA dehydrogenase activity [18]. In the patient described by Watkins et al [17] with bifunctional protein deficiency im-

TABLE III

Complementation Groups in Patients with a Defect in Peroxisomal $\beta$-Oxidation

\begin{tabular}{llc}
\hline Group & \multicolumn{1}{c}{ Enzyme defect } & Patients \\
\hline 1 & Acyl-CoA oxidase deficiency & 1 and 2 \\
2A & Bifunctional protein deficiency (both hydratase and 3HAD components) & $\begin{array}{c}\text { Patient with established bifunctional } \\
\text { protein deficiency [17] }\end{array}$ \\
2B & Bifunctional protein deficiency, hydratase or 3HAD component of BP & $3,4,5$ \\
2C & Bifunctional protein deficiency, hydratase or 3HAD component of BP & $6,7,8,9,10,11$ \\
3 & Unknown & 12 \\
4 & Unknown & 13 \\
\hline
\end{tabular}

Abbreviation used: 3HAD, 3-hydroxyacyl-CoA dehydrogenase. 
munoblot analysis revealed the complete absence of the protein. Consequently, in this patient the genetic defect leads to a complete loss of both components of the bifunctional protein. The molecular basis of the defect in the two other subgroups must be different and might well be at the level of either a deficiency of the enoylCoA hydratase or 3-hydroxyacyl-CoA dehydrogenase component of the bifunctional enzyme respectively. This explanation provides a rational basis for the observed intragenic complementation. Molecular studies are underway to resolve this important finding.

\section{ACKNOWLEDGMENT}

The Princess Beatrix F und is gratefully acknowledged for financial support.

\section{REFERENCES}

1. Lazarow, P. B., and Moser, H. W. (1995) in The Metabolic and Molecular Basis of Inherited Disease (Scriver, C. R., Beaudet, A. L., Sly, W. S., and Valle, D. S., Eds.), pp. 2287-2324, McGrawHill, New York.

2. Wanders, R. J . A., Schutgens, R. B. H., and Barth, P. G. (1995) J . Neuropathol. Exp. Neurol. 54, 726- 739.

3. Goldfischer, S., Moore, C. L., and J ohnson, A. B. (1973) Science 182, 62- 64.

4. Vanden Bosch, H., Schutgens, R. B. H., Wanders, R. J . A., and Tager, J . M. (1992) Annu. Rev. Biochem. 61, 157- 197.
5. Reddy, J . K., and Mannaerts, G. P. (1994) Annu. Rev. Nutr. 14, 343-370.

6. J ansen, G. A., Mihalik, S. J., Watkins, P. A., Moser, H. W., J akobs, C., Denis, S., and Wanders, R. J . A. (1996) Biochem. Biophys. Res. Commun. 229, 205- 210.

7. Wanders, R. J . A., Denis, S., Ruiter, J . P. N., Schutgens, R. B. H., Van Roermund, C. W. T., and J acobs, B. S. (1995) J . Inher. Metab. Dis. 54, 113- 124.

8. Brul, S., Westerveld, A., Strijland, A., Wanders, R. J . A., Schram, A. W., Heijmans, H. S. A., Schutgens, R. B. H., Vanden Bosch, H., and Tager, J . M. (1988) J . Clin. Invest. 81, 1710- 1715.

9. Souri, M., Aoyama, T., and Hashimoto, T. (1994) Anal. Biochem. 221, 362- 367.

10. Schutgens, R. B. H., Bouman, I. W., Nijenhuis, A. A., Wanders, R. J.A., and Frumau, M.E.J. (1993) Clin. Chem. 39, 16321637.

11. Wanders, R. J . A., Schutgens, R. B. H., and Barth, P. G. (1993) Biochimie 75, 269- 279.

12. Vanhove, G. F., Van Veldhoven, P.P., Fransen, M., Denis, S., Eyssen, H. J ., Wanders, R. J . A., and Mannaerts, G. P. (1993) J . Biol. Chem. 268, 10335- 10344.

13. Roscher, A. A., Hoefler, S., Hoefler, G., Paschke, E., Paltauf, F., Moser, A., and Moser, H. W. (1989) Pediatr. Res. 26, 67- 72.

14. Poll-The, B. T., Skjeldal, O. H., Stokke, O., Poulos, A., Demaugre, F., and Saudubray, J . M. (1989) Hum. Genet. 81, 175- 181.

15. McGuiness, M.C., Moser, A.B., Moser, H.W., and Watkins, P. A. (1990) Biochem. Biophys. Res. Commun. 172, 364- 369.

16. Paton, B. C., Sharp, P. C., Crane, D. I., and Poulos, A. (1996) J . Clin. Invest. 97, 681-688.

17. Watkins, P. A., Chen, W. W., Harris, C. J ., Hoefler, G., Hoefler, S., Blake, D. C., Balfe, A., Kelley, R. I., Moser, A. B., Beard, M. E., and Moser, H. W. (1989) J . Clin. Invest. 83, 771- 777.

18. Osumi, T., and Hashimoto, T. (1980) J . Biochem. 87, 1735- 1746. 